\title{
LINIERISASI SENSOR THERMISTOR NTC MENGGUNAKAN PERANGKAT LUNAK DENGAN METODE LOGARITMIK
}

\author{
Wahyu Budi Mursanto, Hartono Budi Santoso, Sri Utami \\ Jurusan Teknik Konversi Energi - Politeknik Negeri Bandung \\ Email :wahyumursanto@gmail.com, hartono@esi-labs.com, utamiwu@yahoo.com
}

\begin{abstract}
Abstrak
Hubungan resistansi thermistor dengan temperatur merupakan fungsi eksponsial dan biasa dinyatakan dalam Persamaan Beta, namun relasi tersebut benar apabila temperatur yang digunakan adalah dalam satuan derajad Kelvin. Dalam penelitian ini akan dicari suatu relasi tegangan hasil pengukuran dengan temperatur, namun dalam satuan derajad Celcius. Untuk itu akan dicari suatu model matematik thermistor yang mempunyai fungsi dengan karakteristik eksponensial yang memenuhi relasi tersebut. Teknik linierisasi dilakukan dengan mencari fungsi invers dari model matematik tersebut yang merupakan fungsi logaritmik untuk mendapatkan kembali nilai temperatur yang diinginkan. Hasil penelitian memperlihatkan bahwa model matematik dengan fungsi Gompertz plus konstanta memberikan kecocokan yang paling sesuai antara model matematik dengan sebaran data. Dengan menggunakan metoda linierisasi secara software menggunakan arduino diperoleh hasil ketelitian pembacaan temperatur yang paling baik dengan derajad kesalahan $\pm 0,04{ }^{\circ} \mathrm{C}$ pada rentang pengukuran $10^{\circ} \mathrm{C}$ sampai dengan $90^{\circ} \mathrm{C}$.
\end{abstract}

Kata Kunci : Thermistor, NTC, non-linier, linierisasi, logarithmik

\section{PENDAHULUAN}

Thermistor merupakan salah satu sensor temperatur yang mempunyai respon waktu yang cepat, serta bentuknya yang fleksibel sehingga banyak diaplikasikan di dunia industri atau penggunaan sehari-hari. Sensor thermistor dapat mempunyai ukuran yang sangat kecil, ringan, dengan berbagai bentuk yang beraneka ragam. Karena bentuknya yang dapat kecil dengan sensitivitas yang tinggi, maka sensor ini bisa digunakan untuk mengukur perubahan temperatur dengan cepat.

Dengan bentuk yang kecil, maka konstanta waktu (time constant) dari sensor ini menjadi lebih kecil. Dengan demikian, waktu pengukuran akan menjadi lebih cepat pula. Namun kelemahan dari sensor thermistor mudah pecah (fragile) dan jangkauan temperaturnya terbatas, jika dibandingkan dengan sensor temperatur lainnya seperti thermokopel atau PT-100.

Thermistor yang digunakan pada penelitian ini mempunyai koefisien resistansi yang negatif atau biasa disebut dengan NTC (Negative Temperature Coefficient). Artinya, dengan naiknya temperatur, nilai resistansi yang terjadi akan semakin kecil. Perubahan yang terjadi adalah non-linier (eksponensial).
Gambar 1. memperlihatkan karakteristik perubahan resistansi terhadap temperatur dari thermistor (NTC) yang non-linier.

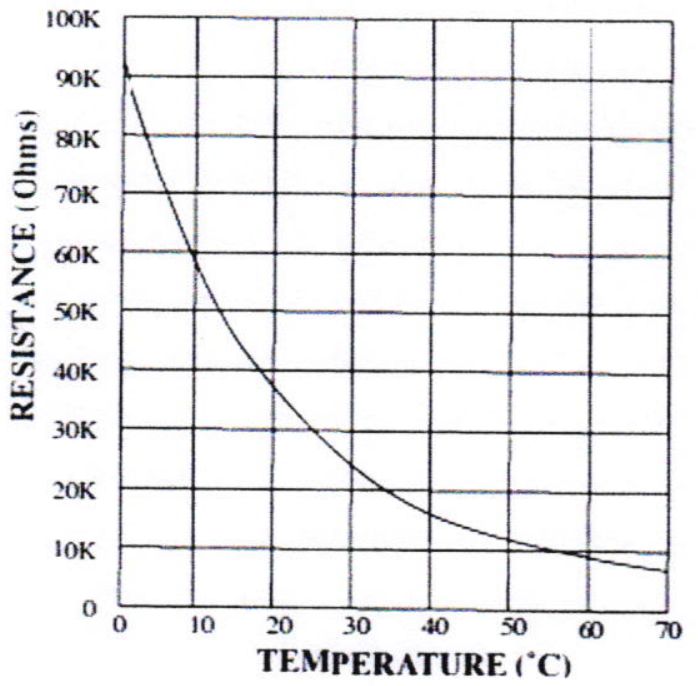

Gambar 1. Karakteristik Thermistor NTC

Pada aplikasi untuk pengukuran temperatur yang lebih teliti, karakteristik yang non-linier dari sensor temperatur merupakan persoalan, untuk itu diperlukan teknik linierisasi agar mempermudah dalam pengukuran. Metoda linierisasi dapat dilakukan dengan menggunakan perangkat keras ataupun perangkat lunak. 
Keuntungan metoda linierisasi dengan menggunakan perangkat keras adalah bahwa biasanya pengukuran yang dilakukan tidak ada waktu tunda dan biaya yang dikeluarkan menjadi lebih murah. Kerugiannya adalah bahwa biasanya ketelitian yang diperoleh agak kurang bila dibandingkan dengan menggunakan perangkat lunak (software). Untuk memperoleh ketelitian yang setara dengan cara menggunakan perangkat lunak, maka rangkaian hardware yang diperlukan menjadi lebih kompleks dan mahal.

Keuntungan menggunakan perangkat lunak semua persoalan yang ada dapat diselesaikan melalui improvisasi secara luas menggunakan berbagai perhitungan dan algoritma dikarenakan kemudahan fasilitas pada perangkat komputer, sehingga akan menghasilkan hasil yang lebih teliti. Kerugiannya adalah masih memerlukan biaya yang mahal dan jika algoritma yang digunakan tidak tepat, akan membuat waktu komputasi mejadi lebih lama, sehingga berakibat pada penundaan pengukuran.

\section{TINJAUAN PUSTAKA}

Metoda linierisasi dengan menggunakan perangkat keras (rangkaian elektronik) dapat dilakukan dengan cara merangkai sensor secara parallel [1], secara seri [2], atau dengan menggunakan jembatan Wheatstone [3]. Linierisasi secara hardware juga bisa dilakukan dengan menggunakan metoda Op-Amp [4], atau menggunakan perangkat keras dengan membentuk rangkaian logaritmik [5].

\section{Persoalan pada perancangan perangkat} keras dengan menggunakan penguat logaritmik banyak menemui hambatan, terutama pada pemilihan komponen yang sesuai dan pengaruh perubahan temperatur komponen yang sering mengganggu proses linierisasi.

Dengan semakin maju dan berkembangnya teknologi pemrosesan data dengan menggunakan piranti mikroprosesor (komputer), maka model penguat logaritmik menjadi lebih mudah untuk diimplementasikan melalui perangkat lunak yang mendukung mikroprosesor tersebut. Beberapa penelitian atau teknik linierisasi lain dengan menggunakan perangkat lunak yang sudah dilakukan diantaranya menggunakan Metoda Persamaan Polinomial Adaptif [6]. Teknik ini menggunakan persamaan polinomial berderajad tinggi untuk mencari fungsi asli dan kemudian mencari pendekatan fungsi inversnya. Pendekatan fungsi dilakukan sedikit demi sedikit dengan menggunakan iterasi sampai kemudian diperoleh suatu fungsi yang diinginkan. Tujuan dari algoritma ini adalah mencari nilai koefisien sedemikian rupa sehingga didapatkan nilai rata-rata kuadrat error yang sekecil mungkin. Keterbatasan pada metode ini adalah bahwa ketelitian yang diperoleh didasarkan pada mutu data yang digunakan.

Aplikasi dengan menggunakan perangkat lunak yang lain juga dapat dilakukan dengan metoda Look-up Table [7]. Teknik ini bukan melinierkan sinyal yang ada, tetapi membuat hasil pengukuran seperti apa adanya, berdasarkan pada data titik-titik pengukuran (data temperatur) dan hasil pengukurannya (resistansi atau tegangannya), sehingga dari tabel antara masukan dan keluaran tersebut dapat dibuat suatu konversi secara langsung hubungan antara masukan dan keluarannya.

Cara ini memang menarik dan tidak memerlukan teknik linierisasi, namun ketelitiannya tergantung pada data titik-titik yang sudah ditentukan atau dibuat. Jika titiktitik tersebut tidak ada pada data dari tabel yang sudah dibuat, maka tidak akan keluar nilainya (keluarannya). Kekurangan ini sebenarnya dapat didekati dengan membuat pendekatan garis lurus diantara kedua titik untuk mencari nilai diantara kedua titik tersebut.

Penelitian ini mencoba untuk mencari suatu fungsi yang merupakan fungsi invers dari fungsi karakteristik sensor thermistor. Hubungan antara masukan (temperatur) dan keluaran (resistansi) pada sensor thermistor mempunyai karakteristik sebagai fungsi eksponensial. Fungsi invers dari fungsi eksponensial adalah fungsi logaritmik.

Metoda yang dilakukan pada penelitian adalah dengan merekonstruksi sinyal asli sehingga diperoleh persamaan eksponensialnya. Gambar 2-1 memperlihatkan diagram kotak pengukuran sinyal [6]. 


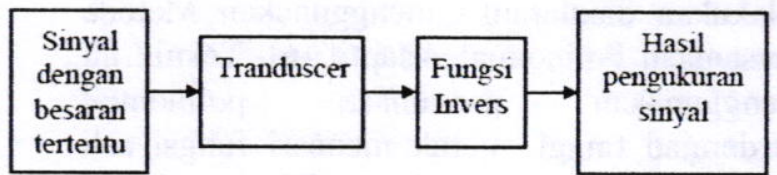

Gambar-2 Pengukuran sinyal

Jika diandaikan bahwa sinyal asli adalah $\mathrm{T}$ (besaran yang diukur adalah temperatur), maka setelah melewati transduser maka sinyal tersebut menjadi suatu fungsi $y=$ $\mathrm{f}(\mathrm{T})$, dengan $\mathrm{f}($.$) adalah karakteristik dari$ transduser atau rangkaian elektronik. Besaran y ini sebenarnya adalah besaran tahanan. Dengan memasukkan pada suatu rangkaian elektronik tertentu (pengkondisi sinyal) dengan fungsi $\mathrm{v}($.) maka fungsi masukan $\mathrm{y}=$ $\mathrm{f}(\mathrm{T})$ akan menjadi fungsi $\mathrm{h}=\mathrm{v}(\mathrm{y})$ atau $\mathrm{h}=$ $\mathrm{v}(\mathrm{f}(\mathrm{T})$ ). Agar dihasilkan pengukuran yang sama dengan sinyal asli yang diukur, maka $h$ harus sama dengan $T$ atau $v(f(t))=T$. Untuk memperoleh ini, maka fungsi $\mathrm{v}($.) harus merupakan fungsi invers dari $f($.$) .$

\section{METODOLOGI}

Thermistor yang mempunyai karakteristik non linier sudah memiliki persamaan dasar yang merupakan fungsi eksponensial. Model matematika dari thermistor diperlihatkan pada persamaan-1, disebut sebagai Persamaan Beta [8].

$R_{T}=R_{0} e^{\beta\left(\frac{1}{T}-\frac{1}{T_{0}}\right)}$

\section{Dengan :}

$\mathrm{R}_{\mathrm{T}}=$ Nilai tahanan $(\Omega)$ pada temperatur $\mathrm{T}$

$\mathrm{R}_{0}=$ Nilai tahanan $(\Omega)$ pada temperatur ambien

$\beta=$ Konstanta (material thermistor)

$\mathrm{T}_{0}=$ Temperatur ambient $\left({ }^{\circ} \mathrm{K}\right)$

$\mathrm{T}=$ Temperatur $\left({ }^{\circ} \mathrm{K}\right)$

Berdasarkan pada persamaan-1 tersebut di atas, maka fungsi invers dengắn mudah dapat diperoleh dan ditunjukkan pada persamaan-2.

$T=\frac{\beta}{\ln \left(\frac{R_{t}}{R_{0}}\right)+\left(\frac{\beta}{T_{0}}\right)}$.

Jika nilai Rt dapat dikonversikan menjadi nilai tegangan, maka secara prinsip nilai $\mathrm{T}$ dapat diperoleh berdasarkan pada persamaan-2.. Masih mirip dengan hal yang dijelaskan di atas, adalah suatu persamaan thermistor yang ditemukan oleh Prof. Steinhart dan Dr. Hart sebagaimana ditunjukkan pada persamaan-3 [9].

$\frac{1}{T}=A+B \ln [R]+C[\ln (R)]^{3}$

\section{$\mathrm{T}$ dalam derajad Kelvin dan $\mathrm{R}$ dalam $\mathrm{Ohm}$}

Persamaan-3 ini dikenal dengan persamaan Stenhart-Hart. Persamaan ini bahkan langsung memberikan nilai $\mathrm{T}$ jika $\mathrm{R}$ diketahui. Namun, persamaan-1 sampai 3 hanya berlaku untuk domain temperatur dalam derajad temperatur mutlak (derajad Kelvin). Artinya, untuk memperoleh nilai temperatur dalam derajad Celcius, maka nilai $\mathrm{T}$ harus dikurangi dengan nilai 273. Jika solusi ini diterapkan, maka hal ini sudah menjawab persoalan yang ada. Namun, bukan hal ini yang diinginkan dalam penelitian ini.

Penelitian ini menghendaki adanya suatu hubungan langsung keluaran sistem (tegangan) terhadap temperatur masukan dalam domain derajad Celcius. Karena thermistor merupakan fungsi non linier yang merupakan fungsi eksponensial, maka model matematik yang baru ini belum tentu sama dengan model seperti pada persamaan-1. Persamaan atau model matematik yang baru ini yang akan dicari untuk kemudian akan dihitung fungsi inversnya.

Rekonstruksi sinyal akan dilakukan dengan menggunakan aplikasi yang sudah banyak tersedia, misalnya menggunakan fasilitas pada aplikasi Excell.. Dari hasil rekonstruksi tersebut akan diuji terlebih dahulu, apakah hasil rekonstruksi sudah memberikan hasil yang memadai apa belum. Hal ini dilakukan dengan cara memasukkan kembali nilai-nilai masukan dan harus menghasilkan nilai keluaran yang sama (dengan derajad ketelitian atau toleransi tertentu) berdasarkan data yang ada pada semua jangkauan pengukuran temperatur yang direncanakan. Apabila hasilnya masih tidak memuaskan, maka harus dicari cara sedemikian rupa sehingga model matematik fungsi eksponensial yang benar dapat diperoleh.

Pada penelitian ini jika rekonstruksi tidak menghasilkan suatu fungsi yang tepat, maka hal ini dapat terjadi dikarenakan jangkauan pengukuran yang terlalu besar. Untuk itu, dalam melakuan penyelesaiannya 
akan dibuat suatu konstruksi dengan membagi jangkauan pengukuran yang besar tersebut dalam 2 jangkauan pengukuran atau lebih. Dengan demikian akan diperoleh 2 atau lebih fungsi eksponensial hasil konstruksi sinyal. Cara lain adalah dengan memanfaatkan modelmodel matematik suatu fungsi eksponensial yang sudah ada dan mencoba mencocokkan apakah model matematik tersebut cocok atau tidak.

Dengan diperolehnya fungsi eksponensial yang pasti, maka langkah terakhir adalah mencari fungsi inversnya. Fungsi invers akan ditentukan dengan menggunakan perhitungan matematika biasa atau dapat dilakukan dengan menggunakan bantuan program aplikasi yang ada

Penelitian dilakukan dengan membuat rangkaian elektronik (penguat instrumentasi) sehingga sinyal tegangan output yang nonlinier dari thermistor dapat diperoleh pada level yang cukup sesuai dengan level perangkat berikutnya (piranti Arduino Uno (ADC). Sinyal dimasukkan pada piranti Arduino Uno merupakan piranti interface yang menjembatani dunia analog dengan dunia digital sekaligus sebagai pemroses data perhitungan untuk linierisasi. ADC yang digunakan adalah 10 bit, agar resolusi sinyal tegangan (representasi besaran temperatur) yang dihasilkan dapat memadai.

Komputer pribadi (PC) merupakan tempat dimana program dibuat dan di-edit untuk kemudian hasilnya dieksekusi dan disimpan dalam Arduiono Uno. Sekali program dimasukkan ke dalam Arduino maka Arduino sudah dapat digunakan sebagai piranti untuk mengerjakan seperti yang ditulis di program tanpa perlu PC lagi. Jadi fungsi Arduino adalah melakukan pembacaan data dari rangkaian sensor, kemudian mengolah data tersebut sesuai dengan program yang dimasukkan (dalam hal ini memproses hitungan dari fungsi invers model matematik yang sudah dibuat) dan mengirimkan data yang sudah diperoleh (pembacaan temperatur) ke piranti lain seperti LCD, layar PC atau perangkat yang lainnya.

\section{HASIL DAN PEMBAHASAN}

Pengujian pertama adalah melakukan pengujian resistansi thermistor terhadap temperatur. Pengujian ini dimaksudkan untuk mengetahui berapa nilai tahanan pada jangkauan pengukuran yang ditetapkan. Dari tabel-1 tampak bahwa nilai tahanan tertinggi berada pada orde sekitar $33500 \mathrm{Ohm}$ untuk temperatur sekitar $0^{\circ} \mathrm{C}$, dan nilai terendah di sekitar $925 \mathrm{Ohm}$ pada temperatur sekitar $90^{\circ} \mathrm{C}$.

Nilai ini akan bermanfaat untuk merancang penguatan rangkaian sensor agar berada pada jangkauan di sekitar 0 sampai 5 Volt dc. Rangkaian sensor dibuat berdasarkan pada gambar-3.

Tampak bahwa rangkaian pengkondisi sinyal untuk sensor thermistor disusun dari dua penguat. Penguat pertama merupakan penguat membalik dengan penguatan bergantung pada nilai $\mathrm{R}$ sensor dibagi dengan $\mathrm{R}$ input dan hasilnya dikalikan dengan tegangan referensi (Vs). Dengan memilih nilai Vs $=1$ Volt dan Rs sebesar 6,8 k Ohm, maka nilai tegangan keluaran Vout 1 pada penguat tingkat 1 adalah berkisar $-0,1$ Volt sampai dengan $-4,95$ Volt.

Fungsi dari penguat tingkat 2 adalah untuk membalik sinyal sehingga nilainya menjadi positip. Sehingga nilai akhir tegangan di penguat kedua berkisar dari 0,1 Volt sampai 4,95 Volt. jangkauan tegangan ini sudah cukup memadai karena sudah sangat dekat dengan jangkauan tegangan input untuk ADC yang digunakan yaitu dari 0 sampai dengan 5 Volt.

Tabel-1 Pengukuran tahanan sensor

\begin{tabular}{|r|r|r|}
\hline \multicolumn{1}{|c|}{ NO } & \multicolumn{1}{|c|}{$\left.\mathbf{T}^{\circ} \mathbf{C}\right)$} & TAHANAN (OHM) \\
\hline 1 & 0,1 & 33503 \\
\hline 2 & 5,3 & 25563 \\
\hline 3 & 8,2 & 22091 \\
\hline 4 & 10,6 & 19612 \\
\hline 5 & 14,7 & 16080 \\
\hline 6 & 17,5 & 14090 \\
\hline 7 & 20,2 & 12434 \\
\hline 8 & 25,4 & 9825 \\
\hline 9 & 29,6 & 8180 \\
\hline 10 & 35,3 & 6428 \\
\hline 11 & 40,1 & 5275 \\
\hline 12 & 44,8 & 4385 \\
\hline 13 & 50 & 3590 \\
\hline 14 & 55,1 & 2971 \\
\hline 15 & 59,7 & 2515 \\
\hline 16 & 64,8 & 2095 \\
\hline 17 & 70,3 & 1744 \\
\hline 18 & 74,5 & 1520 \\
\hline 19 & 80,2 & 1256 \\
\hline 20 & 85,5 & 1070 \\
\hline 21 & 90,4 & 925 \\
\hline
\end{tabular}

Pengujian berikutnya adalah melakukan kalibrasi rangkaian sensor. Pengujian dilakukan dengan mengganti sensor dengan 
resistor yang sudah ditentukan nilainya pada nilai batas bawah dan batas atas pengukuran.

Tegangan yang dihasilkan harus sesuai dengan yang seharusnya. Jika belum sama dilakukan kalibrasi dengan mengatur resistor potensio sampai diperoleh hasil yang diinginkan.

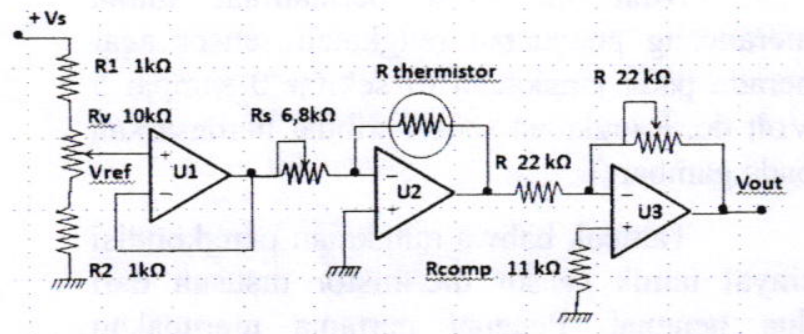

Gambar-3 Rangkaian pengkondisi sinyal sensor

Tabel-2 Hasil pengukuran tegangan versus temperatur

\begin{tabular}{|r|r|r|}
\hline $\mathbf{N U}$ & $\left.I^{\circ} \mathrm{C}\right)$ & I GANGAN $(\mathrm{V})$ \\
\hline 1 & 0,2 & 4,90 \\
\hline 7 & 6,3 & 3,57 \\
\hline 3 & 8,7 & 3,17 \\
4 & 11,4 & 2,77 \\
\hline 5 & 15,0 & 2,333 \\
\hline 6 & 17,7 & 2,054 \\
\hline 7 & 20,5 & 1,804 \\
\hline 8 & $25,-$ & 1,465 \\
\hline 9 & $30,-$ & 1,180 \\
\hline 10 & 34,5 & 0,980 \\
\hline 11 & 40,4 & 0,768 \\
\hline 12 & 45,3 & 0,632 \\
\hline 13 & 50,5 & 0,519 \\
\hline 14 & 54,6 & 0445 \\
\hline 15 & 60,6 & 0,359 \\
\hline 16 & 64,5 & 0,315 \\
\hline 17 & 71,0 & 0,251 \\
\hline 18 & 75,4 & 0,218 \\
\hline 19 & 80,0 & 0,187 \\
\hline 20 & 86,5 & 0152 \\
\hline 21 & $90,-$ & 0,137 \\
\hline & & \\
\hline
\end{tabular}

PENGUKURANTEGANGAN VERSUS TEMPERATUR

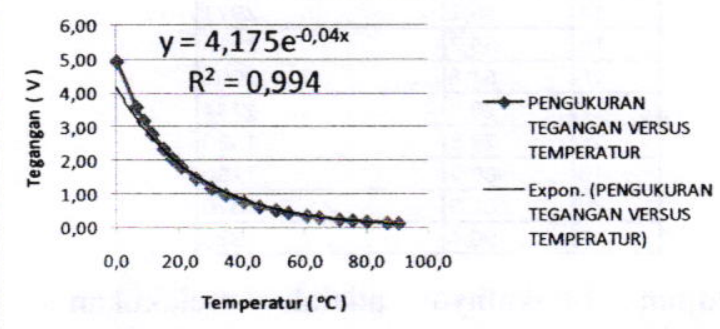

Gambar-4 Kurva tegangan versus temperatur
Setelah terkalibrasi dengan benar, dilakukan pengambilan tegangan keluaran rangkaian untuk berbagai temperatur. Tabel-2 memperlihatkan hasil pengukuran tersebut, sementara gambar-4 memperlihatkan kurva yang dihasilkan dari pengukuran tersebut.

Tampak pula fungsi persamaan yang dihasilkan dengan menggunakan fasilitas pada program Excell. Secara fisik pendekatan fungsi dengan menggunakan fasilitas trendline memperlihatkan kurva yang mendekati data pengukuran. Tabel-3 memperlihatkan hasil perhitungan fungsi invers dari fungsi yang sudah dihasilkan berdasarkan pendekatan menggunakan program Excell.

Tabel-3 Hasil perhitungan fungsi invers dan selisih pengukuran

\begin{tabular}{|r|r|r|r|r|}
\hline NO & $\mathrm{T}^{\circ}{ }^{\circ} \mathrm{C}$ ) & $\begin{array}{r}\text { TEGANGAN } \\
\text { ( V) }\end{array}$ & $\begin{array}{r}\text { T - HITUNG } \\
\left({ }^{\circ} \mathrm{C}\right)\end{array}$ & $\begin{array}{c}\text { ERROR } \\
\left({ }^{\circ} \mathrm{C}\right)\end{array}$ \\
\hline 1 & 0,2 & 4,90 & $-4,0$ & 4,22 \\
\hline 2 & 6,3 & 3,57 & 3,9 & 2,41 \\
\hline 3 & 8,7 & 3,17 & 6,9 & 1,80 \\
\hline 4 & 11,4 & 2,77 & 10,2 & 1,18 \\
\hline 5 & 15,0 & 2,333 & 14,5 & 0,45 \\
\hline 6 & 17,7 & 2,054 & 17,7 & $-0,04$ \\
\hline 7 & 20,5 & 1,804 & 21,0 & $-0,48$ \\
\hline 8 & 25,1 & 1,465 & 26,2 & $-1,07$ \\
\hline 9 & 30,1 & 1,180 & 31,6 & $-1,49$ \\
\hline 10 & 34,5 & 0,980 & 36,2 & $-1,74$ \\
\hline 11 & 40,4 & 0,768 & 42,3 & $-1,91$ \\
\hline 12 & 45,3 & 0,632 & 47,2 & $-1,89$ \\
\hline 13 & 50,5 & 0,519 & 52,1 & $-1,62$ \\
\hline 14 & 54,6 & 0,445 & 56,0 & $-1,38$ \\
\hline 15 & 60,6 & 0,359 & 61,4 & $-0,75$ \\
\hline 16 & 64,5 & 0,315 & 64,6 & $-0,07$ \\
\hline 17 & 71,0 & 0,251 & 70,3 & 0,72 \\
\hline 18 & 75,4 & 0,218 & 73,8 & 1,63 \\
\hline 19 & 80,0 & 0,187 & 77,7 & 2,30 \\
\hline 20 & 86,5 & 0,152 & 82,8 & 3,71 \\
\hline 21 & 90,1 & 0,137 & 85,4 & 4,74 \\
\hline
\end{tabular}

Pada tabel-3 juga diperlihatkan selisih pengukuran temperatur jika dibandingkan dengan data aslinya. Tampak bahwa error berada di antara nilai $0,04{ }^{\circ} \mathrm{C}$ sampai dengan $4,74{ }^{\circ} \mathrm{C}$. Hasil ini masih belum memperlihatkan hasil yang memadai.

Pendekatan fungsi yang diperoleh pada jangkauan pengukuran temperatur yang cukup lebar memperlihatkan hasil yang kurang memadai, untuk itu dicoba dengan membagi jangkauan pengukuran menjadi setengahnya. Dengan cara ini akan diperoleh 2 fungsi yang berbeda. Fungsi yang pertama untuk jangkauan pengukuran dari $0^{\circ} \mathrm{C}$ sampai dengan $50{ }^{\circ} \mathrm{C}$ dan fungsi yang kedua untuk lebih dari 
$50{ }^{\circ} \mathrm{C}$. Gambar-5 dan 6 memperlihatkan kurva dan persamaan fungsi yang dihasilkan. Tabel4 dan 5 memperlihatkan selisih hasil perhitungan.

Tampak bahwa hasil yang diperoleh masih belum memadai juga, karena kesalahan atau error juga masih tinggi. Bahkan, hasil yang diperoleh dengan menggunakan 1 persamaan masih lebih baik dibandingkan dengan menggunakan 2 persamaan.

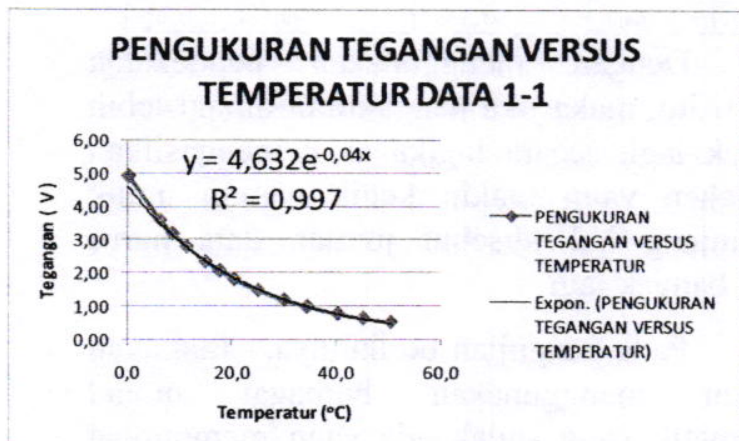

Gambar-5 Kurva tegangan untuk jangkauan temperatur $0 \mathrm{~s} / \mathrm{d} 50^{\circ} \mathrm{C}$

PENGUKURAN TEGANGA VERSUS TEMPERATUR DATA 1-2

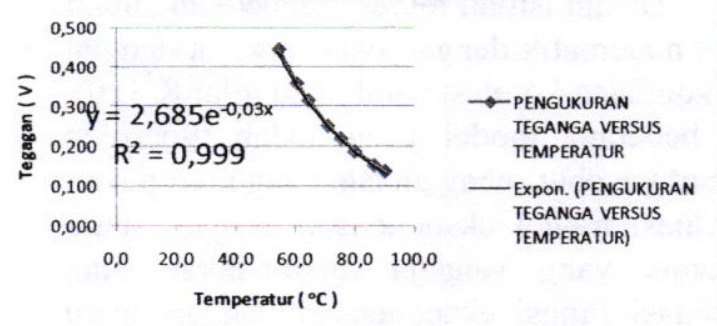

Gambar-6 Kurva tegangan untuk jangkauan temperatur lebih dari $50^{\circ} \mathrm{C}$

Tabel-4 Hasil perhitungan fungsi invers dan selisih pengukuran $0 \mathrm{~s} / \mathrm{d} 50^{\circ} \mathrm{C}$

\begin{tabular}{|r|r|r|r|r|}
\hline NO & T $\left({ }^{\circ} \mathrm{C}\right)$ & $\begin{array}{c}\text { TEGANGAN } \\
(\mathbf{V})\end{array}$ & $\begin{array}{c}\text { T HITUNG } \\
\left({ }^{\circ} \mathrm{C}\right)\end{array}$ & $\begin{array}{c}\text { ERROR } \\
\left({ }^{\circ} \mathrm{C}\right)\end{array}$ \\
\hline 1 & 0,2 & 4,90 & $-1,4$ & 1,62 \\
\hline 2 & 6,3 & 3,57 & 6,5 & $-0,19$ \\
\hline 3 & 8,7 & 3,17 & 9,5 & $-0,80$ \\
\hline 4 & 11,4 & 2,77 & 12,8 & $-1,42$ \\
\hline 5 & 15,0 & 2,333 & 17,1 & $-2,14$ \\
\hline 6 & 17,7 & 2,054 & 20,3 & $-2,63$ \\
\hline 7 & 20,5 & 1,804 & 23,6 & $-3,08$ \\
\hline 8 & 25,1 & 1,465 & 28,8 & $-3,67$ \\
\hline 9 & 30,1 & 1,180 & 34,2 & $-4,08$ \\
\hline 10 & 34,5 & 0,980 & 38,8 & $-4,33$ \\
\hline 11 & 40,4 & 0,768 & 44,9 & $-4,51$ \\
\hline 12 & 45,3 & 0,632 & 49,8 & $-4,49$ \\
\hline 13 & 50,5 & 0,519 & 52,1 & $-1,62$ \\
\hline
\end{tabular}

Tabel-5 Hasil perhitungan fungsi invers dan selisih pengukuran lebih dari $50^{\circ} \mathrm{C}$

\begin{tabular}{|r|r|r|r|r|}
\hline NO & T $\left.^{\circ}{ }^{\circ} \mathbf{C}\right)$ & $\begin{array}{r}\text { TEGANGAN } \\
(\mathbf{V})\end{array}$ & $\begin{array}{c}\text { T HITUNG } \\
\left({ }^{\circ} \mathrm{C}\right)\end{array}$ & $\begin{array}{c}\text { ERROR } \\
\left({ }^{\circ} \mathrm{C}\right)\end{array}$ \\
\hline 14 & 54,6 & 0,445 & 59,9 & $-5,32$ \\
\hline 15 & 60,6 & 0,359 & 61,4 & $-0,75$ \\
\hline 16 & 64,5 & 0,315 & 64,6 & $-0,07$ \\
\hline 17 & 71,0 & 0,251 & 70,3 & 0,72 \\
\hline 18 & 75,4 & 0,218 & 73,8 & 1,63 \\
\hline 19 & 80,0 & 0,187 & 77,7 & 2,30 \\
\hline 20 & 86,5 & 0,152 & 82,8 & 3,71 \\
\hline 21 & 90,1 & 0,137 & 85,4 & 4,74 \\
\hline
\end{tabular}

Hal ini dapat terjadi karena banyaknya data yang digunakan menjadi berkurang setengahnya untuk merekonstruksi fungsi. Sebenarnya kecocokan model dengan data tidak ditentukan oleh banyaknya data, tetapi lebih ditentukan pada kecocokan dengan sebaran data yang ada.

Pengujian selanjutnya dilakukan dengan membagi data menjadi tiga bagian. Pada pengujian ini pendekatan kecocokan fungsi menggunakan fasilitas program aplikasi Lab Fit (sebelumnya menggunakan program aplikas Excell). Program aplikasi Lab Fit merupakan program aplikasi yang mempunyai library model matematik lebih lengkap.

Gambar-7 sampai dengan gambar-9 memperlihatkan kurva karakteristik tegangan versus temperatur dengan jangkauan pengukuran dibagi menjadi tiga bagian. Tabel6 sampai dengan Tabel-8 memperlihatkan hasil dan selisih antara temperatur yang ada dengan hasil perhitungan. Dengan membagi menjadi tiga persamaan eksponensial yang berbeda, maka hasil yang diperoleh lebih bagus lagi, yaitu maksimum error adalah sebesar $1,41^{\circ} \mathrm{C}$.

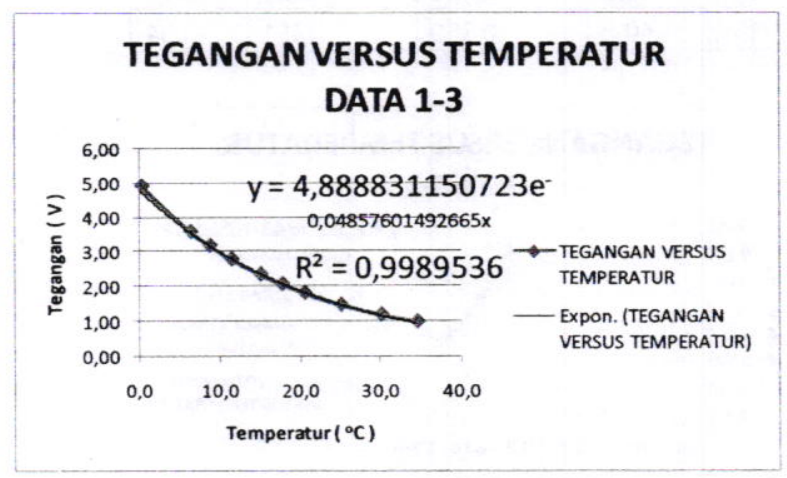

Gambar-7 Kurva tegangan versus temperatur dengan sepertiga jangkauan temperatur yang pertama 
Tabel-6 Hasil perhitungan fungsi invers (menggunakan Lab Fit) dan selisihnya untuk sepertiga jangkauan temperatur yang pertama.

\begin{tabular}{|r|r|r|r|r|}
\hline NO & $\left.\mathrm{T}^{\circ}{ }^{\circ} \mathrm{C}\right)$ & $\begin{array}{r}\text { TEGANGAN } \\
(\mathrm{V})\end{array}$ & $\begin{array}{c}\text { THITUNG } \\
\left({ }^{\circ} \mathrm{C}\right)\end{array}$ & $\begin{array}{c}\text { ERROR } \\
\left({ }^{\circ} \mathrm{C}\right)\end{array}$ \\
\hline 1 & 0,2 & 4,90 & $-0,1$ & 0,26 \\
\hline 2 & 6,3 & 3,57 & 6,5 & $-0,15$ \\
\hline 3 & 8,7 & 3,17 & 8,9 & $-0,23$ \\
\hline 4 & 11,4 & 2,77 & 11,7 & $-0,27$ \\
\hline 5 & 15,0 & 2,333 & 15,2 & $-0,23$ \\
\hline 6 & 17,7 & 2,054 & 17,9 & $-0,15$ \\
\hline 7 & 20,5 & 1,804 & 20,5 & $-0,03$ \\
\hline 8 & 25,1 & 1,465 & 24,8 & 0,30 \\
\hline 9 & 30,1 & 1,180 & 29,3 & 0,84 \\
\hline 10 & 34,5 & 0,980 & 33,1 & 1,41 \\
\hline
\end{tabular}

\section{TEGANGAN VERSUS TEMPERATUR} DATA 2-3

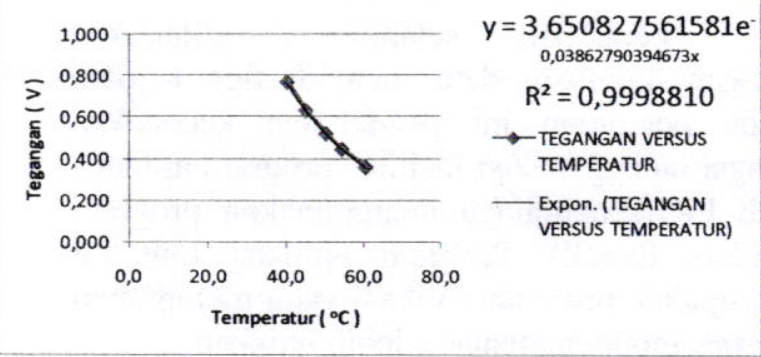

Gambar-8 Kurva tegangan versus temperatur dengan sepertiga jangkauan temperatur yang kedua.

Tabel-7 Hasil perhitungan fungsi invers (menggunakan Lab Fit) dan selisihnya untuk sepertiga jangkauan temperatur yang kedua.

\begin{tabular}{|r|r|r|r|r|}
\hline NO & $\begin{array}{c}\text { T } \\
\left({ }^{\circ} \mathbf{C}\right)\end{array}$ & $\begin{array}{r}\text { TEGANGAN } \\
(\mathbf{V})\end{array}$ & $\begin{array}{c}\text { T HITUNG } \\
\left({ }^{\circ} \mathrm{C}\right)\end{array}$ & $\begin{array}{c}\text { ERROR } \\
\left({ }^{\circ} \mathrm{C}\right)\end{array}$ \\
\hline 11 & 40,4 & 0,768 & 40,3 & 0,06 \\
\hline 12 & 45,3 & 0,632 & 45,4 & $-0,09$ \\
\hline 13 & 50,5 & 0,519 & 50,5 & 0,00 \\
\hline 14 & 54,6 & 0,445 & 54,5 & 0,11 \\
\hline 15 & 60,6 & 0,359 & 60,1 & 0,54 \\
\hline
\end{tabular}

\section{TEGANGAN VERSUS TEMPERATUR} DATA 3-3

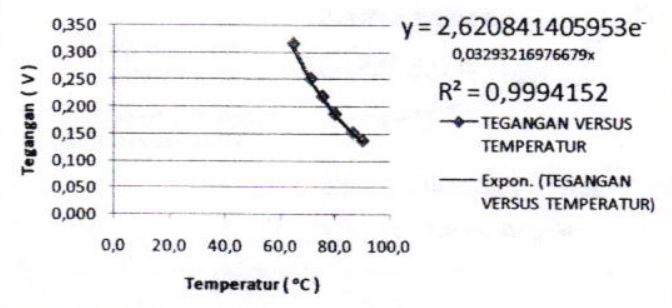

Gambar-9 Kurva tegangan versus temperatur dengan sepertiga jangkauan temperatur yang ketiga.
Tabel-8 Hasil perhitungan fungsi invers (menggunakan Lab Fit) dan selisihnya untuk sepertiga jangkauan temperatur yang ketiga

\begin{tabular}{|r|r|r|r|r|}
\hline NO & $\begin{array}{c}\text { T } \\
\left({ }^{\circ} \mathrm{C}\right)\end{array}$ & $\begin{array}{r}\text { TEGANGAN } \\
(\mathbf{V})\end{array}$ & $\begin{array}{c}\text { T HITUNG } \\
\left({ }^{\circ} \mathrm{C}\right)\end{array}$ & $\begin{array}{c}\text { ERROR } \\
\left({ }^{\circ} \mathrm{C}\right)\end{array}$ \\
\hline 16 & 64,5 & 0,315 & 64,3 & 0,21 \\
\hline 17 & 71,0 & 0,251 & 71,2 & $-0,23$ \\
\hline 18 & 75,4 & 0,218 & 75,5 & $-0,06$ \\
\hline 19 & 80,0 & 0,187 & 80,2 & $-0,23$ \\
\hline 20 & 86,5 & 0,152 & 86,4 & 0,08 \\
\hline 21 & 90,1 & 0,137 & 89,5 & 0,56 \\
\hline
\end{tabular}

Dengan menggunakan pendekatan seperti itu, maka jika pengukuran dibagi lebih banyak lagi, secara logika akan mengasilkan kesalahan yang makin kecil, namun untuk menunjang hal tersebut jumlah data harus lebih banyak lagi.

Pada pengujian berikutnya. dilakukan dengan menggunakan berbagai model matematik yang sudah ada yang mempunyai fungsi eksponensial. Pengujian dilakukan lebih dari 20 model matematik, namun dalam jurnal ini yang ditampilkan adalah model matematik yang paling cocok.

Dalam istilah regresi kecocokan antara model matematik dengan data disebut dengan nilai koefisien korelasi darab atau nilai $\mathrm{R}^{2}[10]$. Dari beberapa model yang sudah diperoleh tersebut tersebut sebagian ada yang merupakan kombinasi model eksponensial dengan suatu konstanta yang sengaja ditambahkan atau kombinasi fungsi eksponensial dengan suatu fungsi linier.

Tabel-9 Resume pencocokan model matematik eksponensial

\begin{tabular}{|c|c|c|c|}
\hline No & NALA FUXGSI & MODEL MLATELATIK & XILAIR R \\
\hline 1 & Eksponen- $3+$ garis lurus & $\mathrm{Y}=\mathrm{A}^{*} \operatorname{EXP}\left(\mathrm{B} T+\mathrm{C}^{*} \mathrm{~T}\right)+\mathrm{D}^{*} \mathrm{I}$ & 0.9996314 \\
\hline 2 & Eksponen-3 + konstanta & $\mathrm{Y}=\mathrm{A}^{*} \operatorname{EXP}\left(\mathrm{B} / \mathrm{T}+\mathrm{C}^{*} \mathrm{~T}\right)+\mathrm{C}$ & 0.9997724 \\
\hline 3 & Eksponen dengan pangkat & $\mathrm{Y}=\mathrm{A}^{*} \mathrm{EXP}\left(\mathrm{B}\left(\mathrm{T}^{\prime} \mathrm{C}\right)\right)$ & 0.9997824 \\
\hline 4 & Eksponen-2 + garis harus & $\mathrm{Y}=\mathrm{A}^{*} \mathrm{EXP}\left(\mathrm{B}^{*} \mathrm{~T}+\left(\mathrm{C}^{*}\left(\mathrm{~T}^{\wedge} 0.5\right)\right)+\mathrm{D}^{*} \mathrm{~T}\right.$ & 0.9998887 \\
\hline 5 & Eksponen-2 + konstanta & $\mathrm{Y}=\mathrm{A} * \operatorname{EXP}\left(\mathrm{B}^{*} \mathrm{~T}+\left(\mathrm{C}^{*}\left(\mathrm{~T}^{\wedge} 0.5\right)\right)\right)+\mathrm{D}$ & 0.9999267 \\
\hline 6 & Weibull & $\mathrm{Y}=\mathrm{A} \cdot \operatorname{EXP}\left(\mathrm{B}\left(\mathrm{T}^{\prime} \mathrm{C}\right)\right)+\mathrm{D}$ & 0.9999654 \\
\hline 7 & Gaussian & $\mathrm{Y}=\mathrm{A}^{*} \operatorname{EXP}\left(\left((\mathrm{T}-\mathrm{B})^{\wedge}-2\right) \mathrm{C}\right)$ & 0.9999825 \\
\hline 8 & Gaussian + konstanta & $Y=A^{*} \operatorname{EXP}\left(\left((T-B)^{\wedge} 2\right) C\right)+D$ & 0.9999959 \\
\hline 9 & Gompertz & $\mathrm{Y}=\mathrm{A}^{*} \operatorname{EXP}\left(\mathrm{B}^{*} \operatorname{EXP}\left(C^{*} \mathrm{~T}\right)\right)$ & 0.9999983 \\
\hline 10 & Gompertz + konstanta & $\mathrm{Y}=\mathrm{A}^{*} \operatorname{EXP}\left(\mathrm{B}^{*} \operatorname{EXP}\left(C^{*} T\right)\right)+\mathrm{D}$ & 0.9999999 \\
\hline
\end{tabular}

Tabel-9 memperlihatkan resume hasil yang diperoleh untuk beberapa model matematik dengan fungsi eksponensial. Tampak pada Tabel-9 ada 10 buah model matematik yang mempunyai nilai $\mathrm{R}^{2}$ mendekati 1. Nilai tersebut diurutkan dari yang terkecil sampai yang terbesar. Nilai-nilai koefisien $\mathrm{A}, \mathrm{B}, \mathrm{C}$ dan $\mathrm{D}$ dari masing-masing 
Daftar Simbol :

T: Temperatur, ${ }^{\circ} \mathrm{C}$ atau $^{\circ} \mathrm{K}$.

$V$ : Tegangan, $V($ Volt $)$.

$R$ : Tahanan, $\Omega(\mathrm{Ohm})$.

$\beta$ : Konstanta material thermistor, ${ }^{\circ} \mathrm{K}$.

\section{DAFTAR PUSTAKA}

[1] Mursanto, W.B.\& Rony, F., "Rancang Bangun Transduser Temperatur Menggunakan Sensor Termistor", Jurnal Teknik Energi, Vol. 2 No. 1. Politeknik Negeri Bandung, 2012.

[2] Mursanto, W.B., "Analisis Pengkondisi Sinyal Untuk Sensor Thermistor : Studi Kasus Linierisasi Secara Seri”, Jurnal Teknik Energi, Vol 4 No. 2. Politeknik Negeri Bandung, 2014.

[3] Warsito, "Analisis Rangkaian Pengkondis Sinyal Tahap Awal Pada Sensor Pasif: Studi Kasus Untuk Thermistor Tipe NTC", Jurnal Sains Tek. Vol. 11 No.3. FMIPA Universitas Lampung, 2015.

[4] Aloke, R.S, "Linearization of NTC Thermistor Characteristic Using OPAMP Based In-verting Amplifier",
Thesis master of Electrical Engineering, Jadavpur University, 2012.

[5] Khan, A.A. \& Sengupta, R., “A linier temperatur/Voltage Con-verter Using Thermistor in Logarithmic Network", IEEE Trans. Instrum. Meas. Vol. IM -33 No.1, 1984, pp-2-4.

[6] Puspita,E., "Teknik Perbaikan Karakteristik suatu Sensor yang Non Linier pada Rangkaian Elektronik Menggunakan Metoda Persamaan Polinomial Adaptif', Politeknik Elektronika Negeri Surabaya, 2002.

[7] Bengtsson, L.E., "Look-up Table Optimization for Sensor Linearization in Small Em-bedded Systems", Journal of Sensor Technology, 2012, page. 177184.

[8] Tompkins, W.J. \& Webster J.G., "Interfacing sensor to the IBM PC", New Jersey : Prentice Hall International, (1988).

[9] Steinhart, J. S. \& Hart S. R., "Calibration for Curve Thermistors", Deep-Sea Research and Oceanographic Abstract, Vol. 15 , Issue. 4, 1968, page $497-503$.

[10] Sembiring, R.K., "Analisis Regresi", Bandung : Penerbit ITB, 1995. 